\title{
CONFERENCIA EPISCOPAL DE ANGOLA: ATENCIÓN PASTORAL DE LOS REFUGIADOS Y MIGRANTES
}

\author{
Angola Episcopal Conference: pastoral care of refugees and migrants
}

Avelino Chico*

Desde muy temprano, la Iglesia católica buscó estar al lado de la situación que viven los inmigrantes y refugiados. Sin embargo, su respuesta nunca ha sido uniforme, sino que se ha ido adaptando a los flujos migratorios. En esta perspectiva se incluye lo que la iglesia está haciendo en Angola. El país vivió poco más de cuarenta años de conflicto: entre 1975 y 1991 habían muerto más de 340.000 civiles (Clodfelter, 2017); y entre 1992 y 2002 se registraba 1.000 víctimas al día (Stedman, 2004). Cerca de 500.000 refugiados angoleños se hallaban en los países vecinos, sobre todo en la República Democrática del Congo (RDC) y Zambia (Costa, Sousa, 2018). Con respecto a los emigrantes, hasta 2009 eran poco más de 522.964. El 30\% de estos individuos se había desplazado hacia Portugal (Tinajero, 2009). La cercanía lingüística y el pasado colonial parece haber sido tomada en cuenta por los migrantes. Aparte de jóvenes, entre los emigrantes angoleños que se encontraban en Portugal había migrantes económicos, los que frecuentaban la enseñanza universitaria, las víctimas de la purga del 27 de mayo de $1977^{1}$ y familias con ascendencia lusa que habían huido de la guerra. Entre los desplazados provocados por la guerra hay que añadir los cerca de 5 millones de desplazados internos que existían en el país poco antes del final del conflicto en 2002 (Soares, 2015). Los centros urbanos, sobre todo Luanda, se habían convertido en cobijos de estas personas que no han podido cruzar las fronteras internacionales.

Con todo, a partir de 2002, el mapa migratorio de Angola empieza a cambiar. En este año, se firman los acuerdos de paz y la economía del país registra cifras galopantes. Además de los refugiados y emigrantes que se hallaban en la diáspora, Angola comienza a recibir extranjeros (inmigrantes)

\footnotetext{
Universidade Católica de Angola (UCAN), Rede Jesuíta de África e Madagascar para Justiça e Ecologia. Luanda, Angola. E-mail: avelinochc621@gmail.com. Orcid: 0000-0002-5091-7955.

1 Éstos son los individuos cuyos familiares tuvieron directa o indirectamente alguna conexión con el fracasado golpe de Estado llevado a cabo en Angola. La mayoría era militante del partido MPLA y la persecución política fue protagonizada por esta formación partidaria. Para profundizar en la comprensión de esta cuestión, véase MATEUS, Dalila Cabrita; MATEUS, Álvaro. Purga em Angola: o 27 de maio de 1977. Alfragide: Texto Editores, 2009.
} 
de varias partes del mundo. Entre los extranjeros que llegan al país figuran individuos altamente cualificados, empresarios, los que emigran amparados por el acuerdo de cooperación, los que vienen por cuenta propia, los que traen a sus familias, y los que ven Angola como país de tránsito hacia Sudáfrica, Brasil y Europa. También acuden al país refugiados y solicitantes de asilo procedentes de países vecinos. Otros llegan desde lejos: Ruanda, Burundi, Sierra Leona, Liberia, Costa de Marfil, Sudán, Etiopía, Eritrea, Somalia, Mauritania, República Centroafricana, Siria y Líbano. Con respecto al retorno de los refugiados angoleños, el Programa de Repatriamento Voluntário diseñado para el periodo 2003-2007 preveía el regreso de 420.000 personas (Lopes, 2013). Pero, tras la operación de retorno, 146.814 refugiados decidieron permanecer en el país de acogida. Es decir, 27.073 en la vecina Zambia, 111.589 en la República Democrática del Congo, 5.600 en Namibia y 2.652 en la República del Congo (Lopes, 2013). Con todo, muchos fueron regresando a Angola por cuenta propia a lo largo de estos años.

Tabla 1 - Clase de migrantes (extranjeros) que se halla en Angola

\begin{tabular}{|c|c|c|c|c|}
\hline Clase & Descripción & Acceso al trabajo & Sector de trabajo & Origen \\
\hline $\begin{array}{l}\text { Altamente } \\
\text { cualificados }\end{array}$ & $\begin{array}{l}\text { Contratados en el } \\
\text { país de origen y } \\
\text { con sueldos entre } \\
25 \text { a } 30 \text { mil US\$ } \\
\text { al mes }\end{array}$ & $\begin{array}{c}\text {-Acuerdo de } \\
\text { cooperación } \\
\text {-Contratados por el } \\
\text { Estado }\end{array}$ & $\begin{array}{l}\text {-Petróleo } \\
\text {-Aviación } \\
\text {-Agricultura } \\
\text {-Medicina } \\
\text {-Construcción }\end{array}$ & $\begin{array}{l}\text {-EE.UU. } \\
\text {-Portugal } \\
\text {-Brasil } \\
\text {-Cuba } \\
\text {-China }\end{array}$ \\
\hline Cualificados & $\begin{array}{l}\text { Licenciados y } \\
\text { formación técnica }\end{array}$ & $\begin{array}{l}\text {-Cuenta propia } \\
\text {-Contratados } \\
\text { por empresarios } \\
\text { nacionales }\end{array}$ & $\begin{array}{l}\text {-Universidad } \\
\text {-Hotelería } \\
\text {-Industria } \\
\text {-Asesoría }\end{array}$ & $\begin{array}{l}\text {-Portugal } \\
\text {-Cuba } \\
\text {-Brasil } \\
\text {-Sudáfrica } \\
\text {-Zimbabwe }\end{array}$ \\
\hline Obreros & $\begin{array}{c}\text { Formación técnica } \\
\text { y profesional }\end{array}$ & Cuenta propia & $\begin{array}{l}\text {-Construcción } \\
\text {-Albañilería } \\
\text {-Reparación }\end{array}$ & $\begin{array}{l}\text {-Portugal } \\
\text {-RDC } \\
\text {-Cuba }\end{array}$ \\
\hline Tanteadores & $\begin{array}{c}\text { Trabajo precario y } \\
\text { Ilegan con pocos } \\
\text { recursos }\end{array}$ & Cuenta propia & $\begin{array}{c}\text {-Comercio } \\
\text {-Venta ambulante } \\
\text {-Peluquería } \\
\text {-Cambio informal de } \\
\text { moneda extranjera }\end{array}$ & $\begin{array}{l}\text {-África } \\
\text { (Central y } \\
\text { Occidental) }\end{array}$ \\
\hline $\begin{array}{l}\text { Refugiados y } \\
\text { solicitantes } \\
\text { de asilo }\end{array}$ & $\begin{array}{l}\text { Formación } \\
\text { literaria y } \\
\text { profesional } \\
\text { variada }\end{array}$ & $\begin{array}{l}\text { Tienen prohibido } \\
\text { acceder al trabajo } \\
\text { (Decreto Ejecutivo } \\
273 / 13 \text { de } 26 \text { de } \\
\text { agosto, art. 4) }\end{array}$ & $\begin{array}{c}\text {-Venta ambulante } \\
\text {-Locutorio (en la calle } \\
\text { y al cielo abierto) } \\
\text {-Peluquería } \\
\text {-Comercio (cantina) }\end{array}$ & $\begin{array}{c}\text {-África Central } \\
\text { (RDC) } \\
\text {-África } \\
\text { Occidental }\end{array}$ \\
\hline
\end{tabular}

Fuente: Elaboración propia

La iglesia católica angoleña ha decidido abrir sus brazos y tender sus manos para alentar, expresar y extender su gesto de solidaridad hacia las personas que llegan al país. En 2006, con la intuición de las Hermanas Scalabrinianas, la 
Conferencia Episcopal de Angola y Santo Tomé (CEAST) aprobó la creación de la Comisión Episcopal de Migraciones (CEPAMI) y desde entonces la Comisión se ha ido extendiendo en las diócesis del país. Desde su génesis, el objetivo de la comisión consistía en "organizar e dinamizar a pastoral das migrações a nível nacional e comunitário, promover a transformação das comunidades cristãs em lugares de acolhida de todos os migrantes, sejam eles refugiados, repatriados ou migrantes internacionais, e fortalecer o espírito de itinerância e de pentecostes tão próprio para o povo e a Igreja" (Chiesa, 2017, p. 275). Así, aparte de la hospitalidad, que es uno de los valores éticos de la tradición judeocristiana (Torralba, 2002), así como africana, CEPAMI está impulsando la cultura del encuentro y gestos de movilización ciudadana para la asistencia humanitaria de los migrantes y retornados más desfavorecidos. Asimismo, va suscitando iniciativas de integración de la población extranjera y la sensibilización de la opinión pública para que se trate a cada migrante con dignidad, respeto y como hijo de Dios.

Otros organismos como Cáritas y el Servicio Jesuita a los Refugiados (JRS) también siguen involucrados en la misma labor. Cáritas está involucrada en el estudio sobre las causas de las migraciones y visita de los inmigrantes en situación irregular que se hallan en el Centro de Detención de Extranjeros Ilegales (CDEI). No hace mucho, aunque aún lo siga haciendo con menos vigor, Cáritas asistía a los innumerables retornados y desplazados internos que habían huido de la guerra civil. En cambio, el JRS ayuda en la asistencia jurídica gratuita a los refugiados, solicitantes de asilo y migrantes. JRS también tiene un programa de asistencia pastoral a los migrantes y defensa de los derechos humanos de la población migrante. Igual que Cáritas, en el auge de la guerra civil, JRS acudía a la población nacional huida del interior del país.

\section{Conferencia Episcopal de Angola y Santo Tomé (CEAST)}

La constitución de la jerarquía eclesiástica en Angola fecha desde 1940. Con el impulso del Concilio Vaticano II, que insta la colaboración entre los obispos para que se logre el mayor bien que la Iglesia proporciona a los hombres (Christus dominus, p. 38), se crea en 1967 la Conferencia Episcopal de Angola y Santo Tomé (CEAST). Actualmente CEAST cuenta con 20 diócesis² ${ }^{2}$ La acción social de CEAST va mitigando la situación que afrontan los inmigrantes y refugiados que se encuentran en Angola. A través de su labor que se circunscribe en la pastoral de asistencia, promoción y cooperación, la iglesia angoleña está echando raíces con el fin de favorecer la consolidación de una sociedad que se inspire en los principios del "Reino de Deus". Entre los más visibles resultados figuran la hospitalidad y la acogida de los migrantes, la asistencia jurídica a

2 Diócesis de Benguela, Cabinda, Caxito, Huambo, Dundo, Kuito, Luanda, Lubango, Luena, M’banza Congo, Malange, Menongue, Namibe, N'dalatando, Sumbe, Ondjiva, Saurimo, Uíge, Viana y Santo Tomé. 
los refugiados, el acceso a la vida litúrgica y sacramental, la promoción de cursos de capacitación laboral, la búsqueda de financiación, la implicación de los donantes y migrantes.

Junto con Cáritas nacional y el JRS, los obispos cuentan con el trabajo de otras congregaciones religiosas. CEPAMI es el organismo por excelencia que coordina la pastoral de las migraciones. La organización fue creada con el impulso indiscutible de las Hermanas Scalabrinianas. La comisión empezó por estar incorporada en la Comisión Episcopal Justicia y Paz $^{3}$ y sus actividades se limitaban a la arquidiócesis de Luanda. Esto data cuando Angola todavía se encontraba sumergida en la guerra civil. Además, el saldo migratorio del país era negativo ya que el número de individuos que abandonaba el país (emigrantes) era superior al que entraba (inmigrantes). Sin embargo, tras la guerra, la economía del país comenzó a crecer y muchos miraban a Angola como el El Dorado en África subsahariana. A partir de 2002 el saldo migratorio ya era positivo. En 2004, ya se diseña los 'esqueletos' para la pastoral migratoria y, tras su creación, en 2006, CEPAMI se fue afirmando como una comisión de ámbito nacional. La tabla 2 refleja el repunte migratorio de Angola del año 1990 al año 2017. A su vez, la tabla 4 indica los sectores económicos donde se hallan los migrantes y los refugiados.

El contexto de los flujos migratorios se iba complicando cada vez más con la respuesta de la sociedad, sobre todo de las entidades políticas, anclada en el temor, los prejuicios y las barreras administrativas (como la rigidez de la ley de extranjería condicionada al interés nacional). La Conferencia Episcopal de Angola se planteó crear una comisión que atendiese las inquietudes de los migrantes. En realidad, CEAST no hizo más que seguir la praxis pastoral hacia los emigrantes e itinerantes plasmada en los documentos pontificios. Entre ellos se nombra la Constitución apostólica Exsul familia (Pío XII, 1952), Pastoralis migratorum cura (Pablo VI, 1969), la Instrucción de la Sagrada Congregación de los Obispos (1969) y la Instrucción pastoral Erga migrantes caritas Christi (2004). Igualmente, no hizo más que apropiarse y unirse a la movilización que ya estaba presente en la tradición de la Iglesia en África.

La exhortación apostólica postsinodal Ecclesia in Africa ya ponía de manifiesto las dificultades que afronta el continente: "una miseria espantosa,

\footnotetext{
3 Tras el recrudecimiento de los flujos migratorios hacia Angola, CEPAMI quedó desvinculada de la Comisión Episcopal Justicia y Paz. La especificidad de su labor convierte a la Comisión Episcopal de Migraciones (CEPAMI) en el organismo por excelencia a lidiar con el tema de las migraciones en el país. Aunque los flujos hacia Angola siguen en alza, sobre todo de inmigrantes y refugiados oriundos de países vecinos, en la Segunda Asamblea Plenaria Anual, que tuvo lugar del 19 al 23 de noviembre de 2018, los obispos de la CEAST volvieron a reincorporar CEPAMI en la Comisión Episcopal Justicia y Paz. La pretensión de los obispos es que la cuestión migratoria sea tratada desde diferentes perspectivas, siendo una de ellas la de la justicia social. Por eso la decisión se enmarca en el ámbito del deseo expresado por el papa Francisco de que a la globalización del fenómeno migratorio hay que responder con la globalización de la caridad y de la cooperación.
} 
una mala administración de los escasos recursos de que se dispone, una inestabilidad política y una desorientación social [...] miseria, guerras, desesperación" (41). En realidad, son estos problemas que sirven de factor de expulsión de los migrantes. Por eso, sigue el documento, África "posee una múltiple variedad de valores culturales y de inestimables cualidades humanas, que puede ofrecer a las Iglesias y a toda la humanidad [...] las culturas africanas tienen un agudo sentido de la solidaridad y de la vida comunitaria" (43). Para poner en marcha estos valores, los obispos africanos criaron en 2010 una comisión de trabajo (Africa Working Group on Migration) con el intuito de reflexionar sobre las causas y las respuestas a los flujos migratorios (CECAM, 2012). La dicha reflexión cuenta con la contribución de la Pontificia Sección de Migrantes y Refugiados y del Comité Internacional Católico de Migración (ICMC, en acrónimo inglés). Todo esto ocurre cuando las cifras de migrantes, refugiados, solicitantes de asilo y de las víctimas de la trata siguen en alza. Las tablas 2, 3 y 4 resaltan las cifras de inmigrantes y refugiados que han ido Ilegando a Angola. Asimismo, describen las principales actividades económicas donde estos migrantes están involucrados.

Tabla 2 - Inmigrantes en Angola (1990-2017)

\begin{tabular}{c|c|c|c|c}
\hline Año & $\begin{array}{c}\text { Inmigrantes } \\
\text { hombres }\end{array}$ & $\begin{array}{c}\text { Inmigrantes } \\
\text { mujeres }\end{array}$ & Inmigrantes & \% Inmigrantes \\
\hline 2017 & 307.681 & 330.818 & 638.499 & $2,14 \%$ \\
\hline 2015 & 304.635 & 327.543 & 632.178 & $2,37 \%$ \\
\hline 2010 & 37.113 & 39.436 & 76.549 & $0,33 \%$ \\
\hline 2005 & 30.240 & 31.089 & 61.329 & $0,31 \%$ \\
\hline 2000 & 23.367 & 22.741 & 46.108 & $0,27 \%$ \\
\hline 1995 & 20.755 & 19.058 & 39.813 & $0,27 \%$ \\
\hline 1990 & 18.142 & 15.375 & 33.517 & $0,26 \%$ \\
\hline
\end{tabular}

Fuente: Countryeconomy.com (2018).

Tabla 3 - Solicitantes de asilo y refugiados en Angola (1990-2018)

\begin{tabular}{c|c|c}
\hline Año & Solicitantes de asilo & Refugiados \\
\hline 1990 & ------ & 11.557 \\
\hline 1995 & 3.515 & 10.884 \\
\hline 2000 & 3.936 & 12.086 \\
\hline 2005 & 3.034 & 13.984 \\
\hline 2010 & 5.568 & 15.155 \\
\hline 2015 & 12.270 & 15.555 \\
\hline 2018 & 30.000 & 68.436 \\
\hline
\end{tabular}

Fuente: Elaboración propia a partir de Index Mundi (2018). 
Tabla 4 - Actividades desarrolladas por los inmigrantes y refugiados

\begin{tabular}{l|l|l}
\hline \multicolumn{1}{c|}{ Oficio/actividad } & \multicolumn{1}{c}{ Rasgos } & \multicolumn{1}{c}{ País/Región de procedencia } \\
\hline Cantina & Venta de víveres \& kit escolar & África Occidental, China \\
\hline Construcción & $\begin{array}{l}\text { Vivienda, proyectos económicos, } \\
\text { sanitarios, sociales y deportivos }\end{array}$ & China, Brasil, Portugal \\
\hline Salones de belleza & “Clínicas” de estética callejeras & África Central (RDC, Congo) \\
\hline Zunga & Venta ambulante & África Central, Occidental, China \\
\hline Kínguila & Cambio informal de divisas & África Occidental y Central \\
\hline Candongueiro & Transporte de pasajero & África Central (RDC) \\
\hline Roboteiro & Trabajo físico y manual & África Central (RDC) \\
\hline Mecánica & Talleres de coches, motos & África Central, China \& Portugal \\
\hline Alquiler de móviles & Telefonía móvil & África Central (RDC) \\
\hline Hostelería & Bar, restaurante, roulotte & Portugal, China, Brasil, RDC \\
\hline Kónicas & Estudios fotográficos, informática & Corea, China, Vietnam, RDC \\
\hline Tiendas & $\begin{array}{l}\text { Venta de muebles, } \\
\text { electrodomésticos, informática y } \\
\text { neumáticos }\end{array}$ & $\begin{array}{l}\text { Líbano, Portugal, China, India, } \\
\text { Mauritania }\end{array}$ \\
\hline
\end{tabular}

Fuente: Elaboración propia.

La Iglesia católica siempre ha querido prestar una atención diferenciada a los inmigrantes y refugiados, ya que su condición exige especial atención. Además, muchos no podrían ser acogidos en los servicios ordinarios pensados más bien para la población autóctona y sedentaria. En el contexto migratorio de Angola, algunos inmigrantes y refugiados, sobre todo los procedentes de África Occidental, no son católicos, sino musulmanes; mientras que otros pertenecen a las comunidades cristianas evangélicas. CEPAMI no es ajena a esa realidad, por eso, introduce con urgencia el componente intercultural, ecuménico e interreligioso en la pastoral de movilidad humana. Aparte de diferentes congregaciones religiosas, dicha pastoral envuelve otras confesiones religiosas (Jensen, Pestana, 2010): Ios Jesuitas que prestan apoyo jurídico a los refugiados; los Espiritanos que trabajan por la educación, justicia y paz; los Salesianos que están involucrados en la formación profesional y reintegración social de los desplazados internos y retornados; los Verbitas que tutelan a menores no acompañados y niños de la calle; los Dominicos que se preocupan con el tema de los derechos humanos; las Teresianas y la Congregación de San José de Cluny que contribuyen en la promoción humana de la mujer; y las Scalabrinianas que se destacan por ser las líderes imbatibles en la labor a favor de los migrantes, sobre todo la mujer migrante y refugiada. 
En un primer momento, CEPAMI se preocupó por organizar la 'casa' y, a la vez, formar líderes que llevaran adelante la pastoral migratoria. Tras esto, empezó a implantar las semillas de la comisión en las diócesis y parroquias. Atendiendo a la especificidad de la movilidad humana se creó en el seno de la comisión algunos sectores específicos. Entre ellos se destaca el sector o la pastoral del mar, carretera, refugiados, turismo, santuarios y aeropuerto. Además de los órganos administrativos y centrales, CEPAMI trabaja en estrecha colaboración con instituciones de la sociedad civil, organizaciones nacionales e internacionales. En 2016, con el impulso incondicional de CEPAMI, se instituye la Rede de Protecção ao Migrante e ao Refugiado. La red integra diferentes organismos de la sociedad civil. Éstos son: CEPAMI, Cáritas de Angola, JRS, Centro de Investigação do Direito (CID/FDUCAN), Comissão Episcopal de Justiça e Paz, Voluntariado Internacional para o Desenvolvimento (VIS), Salesianos de Dom Bosco, ACNUR, Comissão Episcopal da Comunicação Social da CEAST, Irmãs Missionárias Scalabrinianas, Organização Internacional para as Migrações (OIM), Associação OMUNGA, Sociedade do Verbo Divino y Radio Eclesia.

El objetivo de la red consiste en "trabalhar em rede para melhor acompanhar, servir, defender e promover a integração dos migrantes e refugiados em Angola [...] Trabalhar em conjunto para ampliar a área de actuação na protecção do Migrante e Refugiado"4. Además de migrantes y refugiados, los destinatarios de las labores de la red son las víctimas de la trata, los menores no acompañados y los retornados (ex refugiados angoleños). A través de las diócesis, CEPAMI ya ven coordinando algunas de esas actividades a favor de los migrantes y refugiados: talleres de formación para los agentes de pastoral de movilidad humana, acogida de migrantes, enseñanza del portugués, formación en culinaria, pastelería, decoración, mecánica y electricidad; asesoría jurídica y visitas al Centro de Detención de Extranjeros. También se está favoreciendo la celebración litúrgica y sacramental de los migrantes y sus familias. Asimismo, se fueron impulsando las misas en las lenguas nativas de los migrantes ${ }^{5}$.

\section{Cartas pastorales}

CEAST no posee todavía una instrucción o carta pastoral que trate específicamente sobre la cuestión migratoria del país ${ }^{6}$. Con todo, tiene

\footnotetext{
4 Información compartida por Ir. Neide Lamperti, Secretaria Ejecutiva de CEPAMI (25/10/19).

5 En la Parroquia de San Francisco de Assis (Diócesis de M’Banza) hay misa en francés los domingos, en la Parroquia de Santa Ana (Arquidiócesis de Luanda) misa en inglés los domingos y en la Parroquia de Nuestra Señora del Carmo (Arquidiócesis de Luanda) también hay misa vespertina en inglés los sábados. Mientras en la Parroquia de Santa Ana acuden sobre todo los migrantes nigerianos, a la Parroquia de Nuestra Señora del Carmo se dirige el personal diplomático.

6 Aunque no hemos podido encontrarla, se afirma que los bispos escribieron un mensaje con el
} 
innumerables mensajes sobre la situación social y económica del país. Al tratarse de un fenómeno social, las migraciones son tratadas en estos mensajes de manera indirecta. Los cuatro mensajes que recogen el periodo del pico migratorio más importante que el país ha conocido (desde 2002 hasta la actualidad) son: primero, Por uma justiça económica que fue publicado en 2006. En él, los obispos reflexionan sobre la abundancia económica que el país ha ido experimentando. A la vez, exhortan para que el avance económico suponga también el desarrollo y el progreso de la vida de las poblaciones. Lo que se verifica es que la economía ha ido creciendo, pero sus efectos eran aún exiguos ya que la mayoría de la población seguía viviendo en condiciones precarias. Pese a que no se les mencione directamente, los inmigrantes no cualificados y los refugiados figuran entre los que se encuentran en esta situación. Por eso, los obispos abogan por un "mundo mais humano e inclusivo, onde 'o progresso de uns não seja um obstáculo ao desenvolvimento de outros, nem um pretexto para a sua sujeição'" (CEAST, 2006).

Segundo, Viver e agir em Cristo: dimensão social y fue publicado en 2009. El mensaje está inspirado en 1Cor 9,16, Mt 7,21 y St 2,14-17 donde se habla de la celebración de la fe en Cristo y la dimensión social de la fe. La vida nueva en Cristo tiene implicaciones prácticas. Entre ellas se resalta la conciencia que se ha de tener por la promoción humana como herramienta de evangelización. También figura la gestión de los bienes públicos. El mensaje identifica la mala gestión de los bienes públicos como una de las causas de la pobreza. Para ilustrar esta situación se destacan los ejemplos de Zaqueo y san Agustín como portadores del cambio. Mientras Zaqueo incita a la conversión, Agustín evoca el deseo profundo del corazón humano de vivir en Cristo. Así, los obispos incitan a la conversión del corazón para que muestre cercanía hacia los migrantes. Se trata, asimismo, de transformar la realidad.

Tercero, Perante a situação actual. Se trata de una reflexión sobre la situación social vigente. El documento consta de cinco puntos con una introducción y una conclusión. En la introducción se ofrece el panorama del país que es caracterizado por la falta de verdad en relación a los pasos que se están dando en la reconciliación duradera. En el segundo punto se involucra a la comunicación social en este esfuerzo de divulgación de la verdad. El tercer punto nombra las cuestiones que suscitan la agitación social: la exclusión, la ocupación arbitraria de tierras y la falta de acceso a los recursos alimentares. De esta manera se advierte que "ninguém seja vítima da exclusão nas oportunidades da vida" (CEAST, 2011). El cuarto punto y la conclusión hablan

motivo de la jornada mundial del migrante y del refugiado en el año 2005. El Servicio Jesuita a los Refugiados (JRS) se había empeñado a que esta carta fuera escrita. Sin embargo, pasados estos años, esa labor no tuvo secuencia, sobre todo en el periodo en el que el flujo de migrantes para Angola se había recrudecido. 
sobre el imperativo de que las estructuras sociales no estén vinculadas a ningún partido y la necesidad de que los partidos políticos estén al servicio del país.

Cuarto, Momento actual da nação: o que vimos e ouvimos. El mensaje tiene fecha de marzo de 2016 y su contexto ya es el de la crisis económica. El documento señala con claridad los hechos que enferman la sociedad angoleña. Razón por la cual fue el mensaje pastoral más leído y más comentado. El texto consta de veinte puntos y cada uno enumera un hecho concreto: pobreza, crisis económica financiera, aumento de la brecha entre ricos y pobres, subida de la tasa de mortalidad infantil y politización de las ayudas humanitarias. Estas cuestiones no solo afectan a la población autóctona, sino a los migrantes y a los refugiados que el país acoge. Para paliar la situación de estos colectivos, que de per se ya llevan una vida dolorosa (Guadamillas, 2017), los obispos se presentan como pastores de la gran familia que incluye a todos los extranjeros sin excepción. Igualmente proponen acciones concretas como cultivar la esperanza, superar la indiferencia, la apatía y los intereses individualistas.

Los cuatro documentos que hemos analizado tienen el mérito de destacar la situación social y económica del país. La pobreza y la politización de las estructuras sociales parecen ser los temas más recurrentes. Por ejemplo, la politización tiene que ver con conformar el acceso a los servicios sociales a la militancia del partido en el poder. Aunque lo tienen prohibido, los extranjeros deben mostrar simpatía hacia al partido en el gobierno para que reciban las ayudas que necesiten. Por eso, los obispos critican esa situación. Sin embargo, el hecho de que no haya todavía una instrucción pastoral dirigida a los migrantes también es bastante revelador, pues el número de extranjeros que el país acoge y la situación que éstos viven ya lo justifica. Algunos obispos se pronuncian sobre el tema de manera aislada a través de radiomensajes, pero no es suficiente. Además, el radiomensaje no es lo mismo que un mensaje pastoral emitido por todos los obispos. Parece legítimo que se contemple esa demanda. Los obispos siguen teniendo audacia profética, sus anuncios y denuncias podrían servir de conversión a muchos que miran la migración con desconfianza, indiferencia y rechazo.

\section{Notas finales}

La Conferencia Episcopal de Angola fundó en pleno auge migratorio la Comisión Episcopal de Migraciones (CEPAMI). A través de sus sectores específicos, la comisión se ha ido acercando a los inmigrantes y refugiados. Para ofrecer mayor dignidad a esta gente, los obispos han escrito notas pastorales sobre la situación política, económica y social del país que sensibilizan la opinión pública, clamando por la justicia económica, ciñéndose en los valores democráticos y edificando un mundo más humano, unido y cohesionado. Sin embargo, los flujos migratorios se van complejizando cada vez más y la iglesia 
debe seguir dando su sabia aportación. Entre los retos actuales consta la falta de coordinación entre el Estado angoleño y sus vecinos a la hora de diseñar las políticas migratorias. Las decisiones unilaterales son síntomas de la ausencia de respuestas coordinadas. Otro reto tiene que ver con la proliferación de las mafias, de la que Angola no está exenta. No hay movimientos migratorios sin mafias y éstas se encuentran incrustadas en las fronteras exteriores e interiores del país. Además del lucro fácil, las mafias ponen en peligro la vida de millones de personas. En este sentido, los próximos desarrollos de la iglesia deberían incidir en el análisis de las causas profundas de la migración e involucrar más órdenes religiosas en la asistencia a los migrantes.

También se espera la incidencia de la iglesia en el diseño de políticas económicas que propicien los ajustes en las desigualdades entre los Estados, que fomenten la creación de empleos en los países emisores y que estimulen el desarrollo integral de los individuos. No menos importante, sería la aportación de los obispos de la CEAST escribiendo una carta o instrucción pastoral acerca de las migraciones en Angola. Además de orientaciones prácticas y reflexión teológico-pastoral, la instrucción debería instar a la creación de capellanías y formación del clero en cuestiones migratorias. De igual modo debería iluminar a las autoridades en el diseño de la tan esperada Ley de Inmigración. El país apenas posee la 'Ley de visado'. Por último, se espera que la CEAST siga trabajando con las conferencias episcopales donde proceden la mayoría de los migrantes que se encuentran en Angola. La prioridad debería ser dada a la Conferencia Episcopal Nacional del Congo (CENCO), ya que el 65\% de los migrantes que el país acoge proceden de esta nación vecina.

\section{Referencias}

CEAST. Mensagem pastoral Perante a situação actual. 2011. Disponible en: < http:// www.ceastangola.org/asembleia-plenaria/primeira-assembleia-plenAria-2017/ mensagens-pastorais/perante-a-situaCAo-actual/perante-a-situaCAoactual_2_267_96_0.html >. Acceso en: 06.07.17.

CEAST. Mensagem pastoral Por uma justiça económica. 2006. Disponible en: $<$ http://www.agencia.ecclesia.pt/noticias/documentos/ipor-uma-justicaeconomicai/>. Acceso en: 06.07.17.

CEAST. Mensagem pastoral Viver e agir em Cristo: dimensão social. 2009. Disponible en: $\quad<$ http://www.ceastangola.org/asembleia-plenaria/primeira-assembleiaplenAria-2017/mensagens-pastorais/mensagens-pastorais_0_96.html>. Acesso en: 06.07.17.

CEAST. Nota pastoral sobre o Momento actual da nação: 'o que vimos e ouvimos'. 2006. Disponible en: <http://www.agencia.ecclesia.pt/netimages/file/nota_ pastoral_sobre_o_momento_actual_de_angola.pdf > . Acceso en: 06.07.17. 
CHIESA, Marivane. A presença sócio-pastoral de Irmãs Scalabrinianas (MSCS) em África. REMHU, Revista Interdisciplinar da Mobilidade Humana, Brasília, v. 25, n. 49, p. 273-277, 2017.

CONCILIO ECUMÉNICO VATICANO II. Decreto Christus dominus, sobre el ministerio pastoral de los obispos. 1965.

COSTA, Paulo Manuel; SOUSA, Lúcio. 40 anos de Independências: migrações forçadas e regimes de asilo nos PALOP (1975-2013). Cadernos de Estudos Africanos, v. 35, p. 89-108, 2018.

COUNTRYECONOMY.COM. Angola: International Immigration. 2018. Disponible en: <https://countryeconomy.com/demography/migration/immigration/angola > . Acceso en: 06.07.18.

GUADAMILLAS, Francisco. Europa: entre el miedo y la hospitalidad. Santander: Editorial Sal Terrae, 2017.

INDEX MUNDI. Migration. 2018. Disponible en: < https://www.indexmundi.com/ angola/net_migration_rate.html>. Acceso en: 06.07.18.

JENSEN, Søren; PESTANA, Nelson. O papel das igrejas na redução da pobreza em Angola. CMI Report, v. 1, p. 1-45, 2010.

JUAN PABLO II. Exhortación apostólica postsinodal Ecclesia in Africa, 14.09.1995.

MALO, José. Migraciones y doctrina social de la Iglesia. In: CAAMAÑO, José; CEBOLLADA, Pascual (eds.). Pensamiento social cristiano. Madrid: Universidad Pontificia Comillas, 2015, p. 167-193.

LOPES, Carlos M. Reforçar a gestão de dados sobre as migrações em Angola: avaliação e recomendações. 2013. Disponible en: < http://publications.iom.int/ system/files/pdf/angola.pdf>. Acceso en: 17.10.19.

SECAM. SECAM Establishes Working Group on Migration. 2012. Disponible en: <https://www.ecmmw.org/new/2012/09/09/secam-establishes-working-groupon-migration/>. Acceso en: 18.10.19.

SOARES, Alfredo dos Santos. Migrantes forzosos: contextos y desafíos de 'Responsabilidad de Proteger' en el siglo XXI. Madrid: Universidad Pontificia Comillas, 2015.

TINAJERO, Sandra Paola Alvarez. Angola: Study of the Impact of Remittances from Portugal and South Africa. Geneva: International Organization for Migration, 2010.

TORRALBA, Francesc. Ética del cuidar: fundamentos, contextos y problemas. Madrid: Institut Borja de Bioètica y Fundación Mapfre Medicina, 2002. 